NOTE

\title{
Colonization of turbot tissues by virulent and avirulent Aeromonas salmonicida subsp. salmonicida strains during infection
}

\author{
R. Farto ${ }^{1, *}$, D. L. Milton ${ }^{2}$, M. B. Bermúdez ${ }^{1}$, T. P. Nieto ${ }^{1}$ \\ ${ }^{1}$ Área de Microbiología, Departamento de Biología Funcional y Ciencias de la Salud, Facultad de Biología, \\ Universidad de Vigo, Vigo, Spain \\ ${ }^{2}$ Department of Molecular Biology, Umeå Centre for Microbial Research, Umeå University, Umeå, 901 87, Sweden
}

\begin{abstract}
Preventing disease outbreaks in cultured turbot Psetta maxima L. caused by Aeromonas salmonicida subsp. salmonicida (ASS) requires a better understanding of how this pathogen colonizes its host. Distribution of 1 virulent and 2 avirulent ASS strains in turbot tissues was investigated during early and late stages of infection following an immersion challenge. To track bacteria within the turbot, the ASS strains were tagged with green fluorescent protein (GFP). Both virulent and avirulent strains colonized the epidermal mucus, gills, and intestine within the first $12 \mathrm{~h}$ post challenge, suggesting that these sites may serve as points of entry into turbot. Although the avirulent strains colonized these initial sites in the turbot tissues, they were rarely found in the internal organs and were cleared from the host $4 \mathrm{~d}$ post challenge. In contrast, the virulent ASS strain was found in the liver and kidney as early as $12 \mathrm{~h}$ post challenge and was found in the muscle tissue at very late stages of infection. The virulent strain persisted in all tested host tissues until death occurred $7 \mathrm{~d}$ post challenge, suggesting that ASS must colonize and survive within the turbot tissues for an infection to result in death of the fish. Comparisons of the distribution profiles of both virulent and avirulent strains during early and late stages of an infection in turbot has provided important information on the route and persistence of an ASS infection in this host.
\end{abstract}

KEY WORDS: Aeromonas salmonicida · Persistence - Turbot · Green fluorescent protein · GFP · Immersion challenge

Resale or republication not permitted without written consent of the publisher

\section{INTRODUCTION}

Aeromonas salmonicida subsp. salmonicida (ASS) is the etiological agent of furunculosis, a systemic disease of salmonid fish that causes significant economical losses in aquaculture production. Earlier, ASS was thought to cause disease mainly in salmonids (see reviews by Toranzo et al. 2005, Austin \& Austin 2007). However, ASS was later shown to cause disease in the flatfish turbot Psetta maxima (Nougayrede et al. 1990, Toranzo \& Barja 1992, Pedersen \& Larsen 1996, Pérez et al. 1996, Najimi et al. 2008), but little evidence is available about the route of infection of ASS in this non-salmonid finfish.
Previous ASS infection studies have mostly focused on the localization of ASS in the salmonid host during the early stages of infection ( $5 \mathrm{~d}$ post challenge) and suggested that the gills, skin/mucus, and intestine may be a portal of entry into salmonids (Tatner et al. 1984, Hodgkinson et al. 1987, Effendi \& Austin 1995, Svendsen et al. 1999, Jutfelt et al. 2008). These studies gave only partial information on the mode of infection since they did not determine the localization of ASS during the later stages of infection up to death of the animal. The only study that did investigate ASS infections in Atlantic salmon $12 \mathrm{~d}$ post challenge localized ASS in the kidney but not the intestine (Ferguson et al. 1998). However, this study did not sample 
for ASS in other internal organs and did not analyze the transmission of the bacteria through the internal tissues. Interestingly, Hodgkinson et al. (1987) compared infectivity of virulent and avirulent strains in salmonids but only during the first $24 \mathrm{~h}$ post challenge, showing inconclusive results since the virulent strain showed an avirulent behavior. Thus, additional studies are needed to investigate the fate of both virulent and avirulent ASS strains during the progression of early and late stages of disease. In particular, studies using non-salmonid fish such as turbot will give a broader understanding on how ASS colonizes its host and will provide information for the design of new therapeutic strategies to protect against this pathogen in aquaculture.

The green fluorescent protein (GFP) from Aequorea victoria has been used successfully as a genetic marker for the detection of bacterial pathogens during the infection of fish (Ling et al. 2000, 2001, O'Toole et al. 2004, Welch \& Wiens 2005, Chu \& Lu 2008). In most cases, expression of GFP in the bacterial cell does not interfere with growth or virulence (Chalfie et al. 1994, Valdivia et al. 1996, Ling et al. 2000, Chu \& Lu 2008). In addition, GFP fluorescence, which is induced by UV light, facilitates visualization of bacteria in fish tissues and the quantification of bacterial colonies recovered from infected tissues. In this study, 1 virulent and 2 avirulent ASS strains isolated from turbot were engineered to express GFP as a biomarker and used to infect turbot. Using GFP fluorescence, ASS was tracked in the internal and external tissues of turbot Psetta maxima during early and late stages of infection. The avirulent ASS strains were found mostly in the gills, skin mucus, and intestine during infection but were cleared from all turbot tissues 4 days post challenge, whereas the virulent strain persisted in all external and internal tissues tested until death of the animal after $7 \mathrm{~d}$. These data provide insight on the route and persistence of an ASS infection in the turbot flatfish.

\section{MATERIALS AND METHODS}

Bacterial strains and media. We used 3 ASS strains that were previously isolated from diseased turbot in NW Spain cultured between 2002 and 2004. Based on a preliminary screening for virulence of the isolated ASS strains by bath challenge, 1 virulent (RIM 33.1) and 2 avirulent (RM 274.1 and ACRp 43.1) ASS strains were chosen. The virulence phenotype of these strains was confirmed in this study. The ASS strains were supplied by the Departamento de Microbiología y Parasitología (University of Santiago de Compostela, Spain). Positive identification of the strains was con- firmed using a previously described PCR-based assay developed to identify ASS strains (Byers et al. 2002). The PCR reactions were performed 3 times using a colony from each isolate as a template. For a positive control, ASS type strain CECT 894 was used, and for negative controls, 2 A. hydrophila strains (CECT 398 and ATCC 7966) and an A. sobria strain (ATCC 9071) were used. All CECT strains were obtained from the Spanish Type Culture Collection, which is a general service of the University of Valencia, and ATCC strains were obtained from the American Type Culture Collection. Information about the CECT strains and the ATCC strains can be found on their respective homepages (www.cect.org/english and www.lgcstandardsatcc.org). All Aeromonas strains were grown in Trypticase soy broth (TSB; Cultimed) or on Trypticase soy agar (TSA; Cultimed) and incubated at $18^{\circ} \mathrm{C}$ for $72 \mathrm{~h}$.

Escherichia coli SY327 (Miller \& Mekalanos 1988) was used for all cloning experiments. For mobilization of plasmids into ASS strains, E. coli S17-1 was used (Simon et al. 1983). E. coli strains were grown in Luria broth (Cultimed). Kanamycin (Duchefa) was added to a final concentration of $50 \mu \mathrm{g} \mathrm{ml}^{-1}$ when needed.

Construction of GFP-expressing ASS strains (ASSGFP). To visualize ASS strains during an infection of turbot, a plasmid (pGP704-Km3-gfp) carrying gfp fused to a constitutively expressed promoter was constructed and inserted into the chromosome in the intergenic region where the open reading frames of lafU, a flagellar motor protein gene, and Asa_0387, a membrane bound lytic murein transglycosylase D gene, converge (Reith et al. 2008). Thus, the constitutive promoter used to drive expression of GFP cannot induce expression of the 2 flanking genes, and no mutation was made in an annotated gene. To construct pGP704Km3-gfp, the gfp gene and its promoter were excised from pNQFlaC4-gfp27 (Croxatto et al. 2007) using KpnI and NheI and ligated to the R6K-origin-based suicide vector pGP704-Km3 that was digested with $K p n I$ and $\mathrm{XbaI}$. An ASS chromosomal fragment between lafU and Asa_0387 was amplified by PCR using primers 5'-CGG GGT ACC TAT GGT GTC TGG TCT-3' and 5'-CGG CGG GAT ATC TGG CCA ATT GAG CGC-3', digested with KpnI and EcoRV, and ligated to a similarly digested pGP704-Km3 carrying the gfp gene creating pGP704-Km3-gfp.

Plasmid pGP704-Km3-gfp was mobilized into ASS strains by conjugation. E. coli containing pGP704Km3-gfp was mixed with an ASS strain at a ratio of 1 donor to 10 recipient cells, spotted onto a TSA plate containing $1 \% \mathrm{NaCl}$, and incubated at $18^{\circ} \mathrm{C}$ for $24 \mathrm{~h}$. To select for ASS strains containing pGP704-Km3-gfp, the transconjugants were resuspended in $2 \mathrm{ml} \mathrm{TSB}$, plated onto TSA containing $70 \mu \mathrm{g} \mathrm{ml}^{-1}$ of kanamycin and $25 \mu \mathrm{g} \mathrm{ml}^{-1}$ of chloramphenicol (Sigma), and incu- 
bated at $18^{\circ} \mathrm{C}$ for $5 \mathrm{~d}$. As all 3 ASS strains are resistant to chloramphenicol, this antibiotic served to select for ASS strains and against E. coli, whereas kanamycin was used to select for strains carrying the plasmid. Thus, bacteria resistant to both antibiotics were selected and GFP expression was confirmed by detecting fluorescence after excitation with ultraviolet light (wavelength $312 \mathrm{~nm}$ ). After 87 generations of growth in the absence of kanamycin, the ASS strains carrying pGP704-Km3-gfp were still resistant to $50 \mathrm{\mu g} \mathrm{ml}^{-1}$ of kanamycin and expressed GFP, indicating that the plasmid was stably maintained on the chromosome.

A-layer detection. The presence of the paracrystalline surface array (A-layer) was evaluated by using TSA supplemented with $50 \mu \mathrm{g} \mathrm{ml}^{-1}$ of Congo red (Sigma) as described by Ishiguro et al. (1985). ASS strains, grown overnight in TSB at $18^{\circ} \mathrm{C}$ for $24 \mathrm{~h}$ with shaking, were used to inoculate Congo red plates. The plates were incubated for $48 \mathrm{~h}$ and the presence of an A-layer in a colony was indicated by a red color. In addition, the presence of $\operatorname{vap} A$, which encodes the Alayer protein, was determined for each ASS strain by PCR as described previously (Gustafson et al. 1992). These assays were repeated 3 times. For a positive control, ASS type strain CECT 894 was used, and for negative controls, we used 2 A. hydrophila strains (CECT 398 and ATCC 7966).

Virulence assay. Healthy, unvaccinated turbot Psetta maxima without obvious skin lesions and weighing $11 \mathrm{~g}$ were used for an ASS challenge. Fish were the offspring of turbot reared from an experimental fish farm belonging to University of Vigo (ECIMAT, Marine Sciences Station of Toralla), with no history of disease. Prior to the challenge, several fish from the stock were screened for bacterial pathogens according to routine diagnostic procedures, and 6 fish per strain were held for $2 \mathrm{wk}$ in separate experimental tanks containing 201 of sterile, $18^{\circ} \mathrm{C}$ seawater with a salinity of $33 \%$. For the ASS challenge, ASS strains were grown in TSB $(300 \mathrm{ml})$ for $24 \mathrm{~h}$ at $18^{\circ} \mathrm{C}$, and bacteria were added to each tank with non-circulating seawater to a final concentration of $10^{6}$ bacteria $\mathrm{ml}^{-1}$. The starting bacterial numbers were confirmed by determining colony-forming units (cfu) $\mathrm{ml}^{-1}$ of each tank at time 0. Each fish group was challenged for $1 \mathrm{~h}$, subsequently transferred to tanks with sterile, non-circulating seawater, and monitored for $21 \mathrm{~d}$. From all moribund and dead turbot, the liver and kidney tissues were sampled for bacteria by streaking on TSB plates. After $21 \mathrm{~d}$, fish were euthanized by an overdose of tricaine methane sulfonate (MS-222; Sigma), and tissue samples were analyzed as above. The ASS strains were identified by GFP fluorescence and PCR as described above. Fish exposed only to TSB were used as negative controls. All animal experiments were performed according to laws approved by the Spanish Ethical Committee (Royal Decree 1201/2005, 10 October, on the protection of animals for experimentation and other scientific purposes. BOE 21 October 2005, p 34367-34391).

Distribution of ASS-GFP strains during infection of turbot. Infections were performed by bath challenge as described above except that 24 fish were infected with the ACRp 43.1 strain and 27 fish were infected with the RM 274.1 and RIM 33.1 strains. At various times post challenge $(0,6$, and $12 \mathrm{~h}$, as well as $1,2,3$, $4,7,9$, and $21 \mathrm{~d}$ ), 3 fish were killed by an overdose with MS-222 and various tissue samples were removed aseptically, pooled, and weighed. To localize the ASS strains in the fish, the epidermal mucus layer close to the pectoral fin, the anterior intestine, the liver, the kidney, and muscle close to the caudal fin $\left(1 \mathrm{~cm}^{2}\right)$ were each homogenized in $500 \mu$ l of phosphate buffered saline (PBS). Gills were dissected and swabbed with a sterile inoculating cotton bud for direct plating of bacteria. The number of fluorescent ASS cells in each sample was determined by cfu counts on TSA containing kanamycin $\left(100 \mu \mathrm{g} \mathrm{ml}^{-1}\right)$ after incubation at $18^{\circ} \mathrm{C}$ for $72 \mathrm{~h}$ and expressed as cfu $\mathrm{mg}^{-1}$ of tissue or mucus.

\section{RESULTS}

\section{Construction of ASS-GFP strains}

To compare the distribution of ASS strains in turbot during an infection, 1 virulent and 2 avirulent ASS strains were engineered to express GFP. All strains expressing GFP showed an intense green fluorescence when illuminated with UV light. Expression of GFP in the ASS strains was stable during growth within the turbot without selection, and no growth differences were seen between the ASS strains expressing GFP and the respective parent ASS strain (data not shown).

\section{A-layer detection and virulence of the parent and ASS-GFP strains}

To determine whether GFP expression altered the expression of the A-layer protein, a major virulence factor of ASS strains, each ASS-GFP strain and the respective parent strain were tested for the presence of the A-layer protein and the $\operatorname{vap} A$ gene that encodes it (Table 1). All strains contained the vapA gene as determined by PCR amplification and showed red colonies on TSA containing Congo red, indicating that the A-layer was expressed. To determine the virulence of all strains, turbot challenges were done (Table 1). The GFP expressing strains did not differ in 
Table 1. Aeromonas salmonicida subsp. salmonicida. A-layer detection and virulence of ASS strains with and without green fluorescent protein (GFP) expression. A + sign indicates a red color after growth on Congo red plates and PCR detection of the vapA gene. Accumulated mortality is given as number of dead fish/total number of fish tested. Mortality patterns of all strains were also analyzed and were similar between the parent and GFP-expressing strains (data not shown). The right-most column shows the number of fish positive for ASS/total number of dead or surviving fish tested. Cfu: colony-forming units

\begin{tabular}{|c|c|c|c|c|c|}
\hline \multirow{2}{*}{ Strains } & \multirow{2}{*}{\multicolumn{2}{|c|}{$\begin{array}{l}\text { - A-layer - } \\
\text { Congo vapA } \\
\text { red }\end{array}$}} & \multicolumn{3}{|c|}{ _ Immersion challenge } \\
\hline & & & $\begin{array}{c}\text { Dose } \\
\left(\mathrm{cfu} \mathrm{ml}^{-1}\right)\end{array}$ & Mortality & $\begin{array}{l}\text { ASS } \\
\text { recovery }\end{array}$ \\
\hline ACRp 43.1 & + & + & $7.5 \times 10^{6}$ & $0 / 6$ & $0 / 6$ \\
\hline ACRp 43.1-GFP & + & + & $9.9 \times 10^{6}$ & $0 / 6$ & $0 / 6$ \\
\hline RM 274.1 & + & + & $7.8 \times 10^{6}$ & $0 / 6$ & $0 / 6$ \\
\hline RM 274.1-GFP & + & + & $9.6 \times 10^{6}$ & $0 / 6$ & $0 / 6$ \\
\hline RIM 33.1 & + & + & $4.2 \times 10^{6}$ & $6 / 6$ & $6 / 6$ \\
\hline RIM 33.1-GFP & + & + & $5.2 \times 10^{6}$ & $6 / 6$ & $6 / 6$ \\
\hline
\end{tabular}

virulence to the respective parent strain. Only the RIM 33.1 strain was virulent, causing mortality $7 \mathrm{~d}$ post challenge in all fish used in the trial (Table 1). The virulent strains could be recovered in pure culture from all fish. Clinical signs of the RIM 33.1 strain was included anorexia, abnormal swimming behavior, hemorrhagic lesions on the liver, and ascetic fluid in a few individuals. Fish infected with the ASS ACRp 43.1 and RM 274.1 strains did not die, and bacteria could not be recovered from the fish at the end of the experiment. Bacteria were never detected in the uninfected control group.

\section{Distribution of ASS-GFP strains during infection}

Turbot were infected with either of the 2 avirulent or the virulent ASS-GFP strains, and the distribution of each strain in various tissues was tracked using GFP fluorescence. Both virulent and avirulent strains were recovered as a pure culture from all fish during the early stages of infection, as well as the virulent strain from the last stages of infection. All ASS-GFP strains could be isolated from the skin mucus, gills, and intestine during the first few days of infection (Fig. 1). The avirulent strains, ACRp 43.1-GFP and RM 274.1-GFP, decreased in numbers $2 \mathrm{~d}$ post challenge, could not be found in any tissue $4 \mathrm{~d}$ post challenge, were not found in high numbers in the kidney or liver, were never found in the body muscle, and did not cause mortalities. In contrast, the virulent strain RIM 33.1-GFP was detected in all tissues tested, except body muscle, as early as $12 \mathrm{~h}$ post challenge, persisted in all tissues until death of the fish on Day 7 , and colonized the body muscle during the later stages of infection (Fig. 1). The clinical signs observed in the diseased turbot were the same as those described above. Bacteria were not detected in the uninfected control group at any time during the experiment. The detection limit of this assay was 1 colony per $210 \mathrm{mg}$ of sample.

\section{DISCUSSION}

For the first time, utilization of GFP as a biomarker for detection of ASS strains allowed an analysis of the distribution of both virulent and avirulent strains of this important pathogen during both early $(6$ to $12 \mathrm{~h}$ post chal-
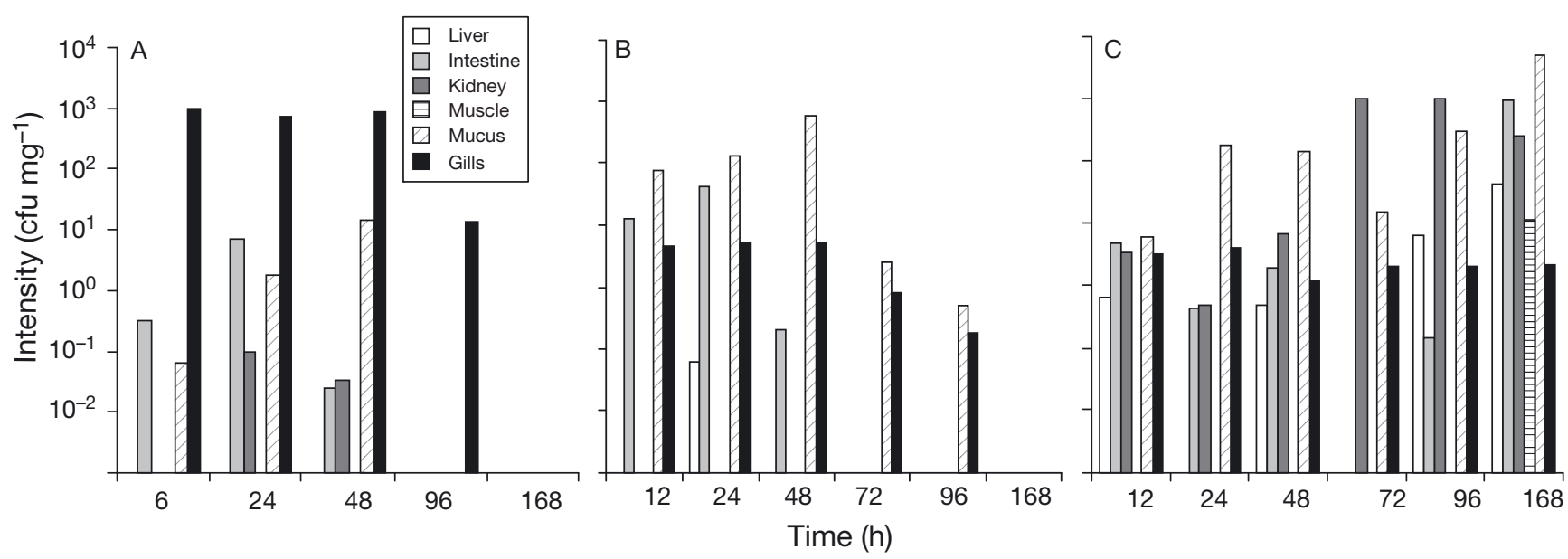

Fig. 1. Aeromonas salmonicida subsp. salmonicida infecting Psetta maxima. Recovery of (A,B) avirulent and (C) virulent ASSGFP strains from turbot tissues after an immersion challenge. (A) ACRp 43.1 (B) RM 274.1, (C) RIM 33.1. The ASS strains in the tissues were enumerated as colony-forming units (cfu) expressing green fluorescent protein (GFP). The low amount of liver dissected at 24 and $72 \mathrm{~h}$ ( 4 to 6 times less than the rest of time points analyzed) is likely the cause of negative detection at these points in the virulent strain RIM 33.1 
lenge) and late stages ( 7 to $21 \mathrm{~d}$ post challenge) of infection in a non-salmonid fish, the flatfish turbot Psetta maxima. Previously, radioactivity was used to visualize ASS in salmonids following infection by immersion; however, that study only followed the infection for $24 \mathrm{~h}$ post challenge (Svendsen et al. 1999). This short period of analysis was not enough to clearly see the difference in distribution patterns between the virulent and avirulent strains used in our study. A lux-based luminescence biomarker has also been used to track the distribution of ASS in salmonids during an infection (Ferguson et al. 1998). In this case, expression of the luminescence genes simplified visualization of ASS strains but reduced the virulence of the strains. In our study, ASS strains were tagged using an R6K-origin-based suicide plasmid that encodes GFP constitutively. The plasmid was integrated into an intergenic region of ASS strains avoiding the disruption of genes that affect virulence or growth. Consequently, the 3 GFP-tagged strains retained the same virulence in turbot as the parent strains and were unaffected in expression of the A-layer protein, which aids adhesion to fish tissues, survival in macrophages, and protection from the host immune system (reviewed by Austin \& Austin 2007). In addition, since the plasmid was integrated into the chromosome, it was stably maintained in the bacterial cell in the absence of antibiotic selection ensuring no loss of the plasmid and thus an accurate count of ASS strains during an infection.

This study is the first investigation of ASS infections using turbot under natural infection conditions. The ASS strain RIM 33.1 used in our study caused the death of infected turbot as previously noted by Pérez et al. (1996) with other strains. In salmonids, ASS was previously shown to attach to epidermal mucus (Ferguson et al. 1998, Svendsen et al. 1999), and it was also suggested that ASS may be detected in the skin mucus of presumptive carrier fish (Cipriano et al. 1994). Similarly in turbot, both the virulent and avirulent GFPtagged ASS strains were found in epidermal mucus during the early stages (12 to $48 \mathrm{~h}$ ) of infection. The virulent strain persisted in the mucus until death of the fish, whereas the avirulent strains were cleared from the mucus $4 \mathrm{~d}$ post challenge. Antibacterial activities of the innate immune system found in the mucus of turbot and other fish species towards ASS are known (Austin \& McIntosh 1988, Fouz et al. 1990). Consequently, although avirulent as well as virulent ASS strains can localize to the epidermal mucus layer, to persist at this site, virulent ASS strains must encode mechanisms to evade the host immunity. These data suggest the possibility that ASS may use the epidermis as a portal of entry into turbot.

In salmonids, ASS has been reported to colonize gill tissue, reaching high bacterial numbers at sites of oxygen exchange (Tatner et al. 1984, Effendi \& Austin
1995, Ferguson et al. 1998, Svendsen et al. 1999). In our turbot model, all ASS strains were detected in the gill tissue at the early stages of infection but, as was shown for the epidermal mucus layer, only the virulent strain persisted in the gill tissue throughout the infection. Due to the high vascularization of the gill tissue, ASS may enter the turbot circulatory system from the gills and then disseminate to other organs.

In several fish species, including Arctic char and Atlantic salmon, ASS is found in the intestines of the animals after a bacterial challenge (Ringø et al. 1997, Svendsen et al. 1999, Lødemel et al. 2001, Petersen \& Dalsgaard 2003). ASS is believed to enter the intestine via the ingestion of contaminated food or seawater (Svendsen et al. 1999, Austin \& Austin 2007) and to translocate the intestinal wall to colonize internal organs (Jutfelt et al. 2008). Similarly in turbot, the GFPtagged ASS strains, both avirulent and virulent, were recovered from the intestine as early as 6 to $12 \mathrm{~h}$ post challenge; however, at these time points, the avirulent strains were rarely detected in any internal organs indicating that virulent ASS strains may also enter turbot via the intestine as previously shown for salmonids.

Internal tissues such as the liver or the kidney were rarely colonized by the avirulent ASS strains, and if so, only very inefficiently. On the other hand, the virulent ASS strain could be found in internal organs as early as $12 \mathrm{~h}$ post challenge, suggesting that virulent ASS strains encode mechanisms that aid invasion of the fish, possibly from several portals of entry. ASS could not be detected in the body muscle of salmonids $5 \mathrm{~d}$ post challenge (Tatner et al. 1984). However, that study did not analyze later time points or dead fish. In the present study, the bacterial challenges were followed until death for the virulent strain ( $7 \mathrm{~d}$ ) and for $21 \mathrm{~d}$ for the avirulent strains. The avirulent ASS strains were never detected in the body muscle, whereas the virulent strain RIM 33.1 was found in the muscle only at $7 \mathrm{~d}$ post challenge, suggesting that detection of ASS in muscle tissue occurs only at the very late stages of infection, and after colonization of kidney and liver. These data further confirm that the avirulent strains do not efficiently penetrate the outer tissues.

Inclusion in this study of 2 avirulent ASS strains, which showed similar results, has provided invaluable information on what is required for a virulent ASS strain to cause disease. By comparing the distribution of avirulent and virulent strains throughout an infection, significant differences were seen on how these strain types interacted with the fish host. Interestingly, both virulent and avirulent ASS strains quickly and efficiently colonized the turbot tissues that were exposed to the seawater environment. However, both avirulent strains were unable to persist in the exposed tissues and were inefficient in crossing the epithelial barriers 
to colonize internal organs and to cause disease. In fact, both avirulent strains were cleared from the animal within $4 \mathrm{~d}$ post challenge. In contrast, the virulent strain colonized exposed tissues and quickly crossed the epithelial barriers leading to infection of internal organs and to death of the animal. These data provide strong evidence that epidermal mucus, gills, and intestine are likely entry points of ASS into turbot and that virulent ASS strains must express mechanisms for evasion of the turbot immune system and for the invasion of the internal tissues to survive in the fish and to cause disease. Several lines of evidence indicate that the A-layer is needed for the evasion of the host immune system and to cause disease (reviewed by Austin \& Austin 2007). However, our avirulent strains, which expressed the Alayer protein both in vitro and in vivo (data not shown), did not cause disease and were cleared from the host, indicating that the A-layer is not a sole determinant of virulence for ASS strains to persist in the host and to cause disease in turbot. This is not a surprising result since avirulent ASS strains that express the A-layer as well as virulent ASS strains that do not express the Alayer have been characterized in other studies (Sakai 1985, Ward et al. 1985, Ellis et al. 1988, Olivier 1990, Thornton et al. 1991, Fernández et al. 1995). Moreover, genetic tagging of the ASS strains with GFP is a useful method for investigating interactions between ASS and animal hosts like turbot. The ASS-GFP strains will also be valuable for investigating ASS behavior in aquatic environments or for studying the viability of live ASS vaccines in fish.

Acknowledgements. This study was supported by grant PGIDIT06RMA26101PR of Xunta de Galicia. We thank M. Lemos (Santiago de Compostela University) and V. Shingler (Umeå University) for kindly providing bacterial isolates and the suicide vector, respectively.

\section{LITERATURE CITED}

Austin B, Austin DA (2007) Bacterial fish pathogens: diseases of farmed and wild fish, 4th edn. Praxis Publishing, Chichester

Austin B, McIntosh D (1988) Natural antibacterial compounds on the surface of rainbow trout, Salmo gairdneri Richardson. J Fish Dis 11:275-277

Byers HK, Gudkovs N, Crane MSJ (2002) PCR-based assays for the fish pathogen Aeromonas salmonicida: I. Evaluation of three PCR primer sets for detection and identification. Dis Aquat Org 49:129-138

> Chalfie M, Tu Y, Euskirchen G, Ward WW, Prasher DC (1994) Green fluorescent protein as a marker for gene expression. Science 263:802-805

Chu WH, Lu CP (2008) In vivo fish models for visualizing Aeromonas hydrophila invasion pathway using GFP as a biomarker. Aquaculture 277:152-155

Cipriano RC, Ford LA, Schacte JH, Petrie C (1994) Evaluation of mucus as a valid site to isolate Aeromonas salmonicida among asymptomatic populations of lake trout (Salvelinus namaycush). Biomed Lett 49:229-233

Croxatto A, Lauritz J, Chen C, Milton DL (2007) Vibrio anguillarum colonization of rainbow trout integument requires a DNA locus involved in exopolysaccharide transport and biosynthesis. Environ Microbiol 9:370-382

Effendi I, Austin B (1995) Uptake of Aeromonas salmonicida by Atlantic salmon (Salmo salar L.). Bull Eur Assoc Fish Pathol 15:115-118

- Ellis AE, Burrows AS, Stapleton KJ (1988) Lack of relationship between virulence of Aeromonas salmonicida and the putative virulence factors: A-layer, extracellular proteases and extracellular haemolysins. J Fish Dis 11:309-323

> Ferguson Y, Bricknell IR, Glover LA, MacGregor DM, Prosser JI (1998) Colonisation and transmission of luxmarked and wild type Aeromonas salmonicida strains in Atlantic salmon (Salmo salar L.). FEMS Microbiol Ecol 27:251-260

> Fernández AIG, Pérez MJ, Rodríguez LA, Nieto TP (1995) Surface phenotypic characteristics and virulence of Spanish isolates of Aeromonas salmonicida after passage through fish. Appl Environ Microbiol 61:2010-2012

Fouz B, Devessa S, Gravningen K, Barja JL, Toranzo AE (1990) Antibacterial action of the mucus of turbot. Bull Eur Assoc Fish Pathol 10:56-59

- Gustafson CE, Thomas CJ, Trust TJ (1992) Detection of Aeromonas salmonicida from fish by using polymerase chain reaction amplification of the virulence surface array protein gene. Appl Environ Microbiol 58:3816-3825

> Hodgkinson JL, Bucke D, Austin B (1987) Uptake of the fish pathogen, Aeromonas salmonicida, by rainbow trout (Salmo gairdneri L.). FEMS Microbiol Lett 40:207-210

Ishiguro EE, Ainsworth T, Trust TJ, Kay WW (1985) Congo red agar, a differential medium for Aeromonas salmonicida, detects the presence of the cell surface protein array involved in virulence. J Bacteriol 164:1233-1237

Jutfelt F, Sundh H, Glette J, Mellander L, Björnsson TB, Sundell K (2008) The involvement of Aeromonas salmonicida virulence factors in bacterial translocation across the rainbow trout, Oncorhynchus mykiss (Walbaum), intestine. J Fish Dis 31:141-151

Ling SHM, Xie L, Lim T, Leung KY (2000) Use of green fluorescent protein (GFP) to track the invasion pathways of Edwardsiella tarda in vivo and in vitro fish models. Microbiology 146:7-19

> Ling SH, Wang XH, Lim TM, Leung KY (2001) Green fluorescent protein-tagged Edwardsiella tarda reveals portal of entry in fish. FEMS Microbiol Lett 194:239-243

> Lødemel JB, Mayhew TM, Myklebust R, Olsen RE, Espelid S, Ringø E (2001) Effect of three dietary oils on disease susceptibility in Arctic charr (Salvelinus alpinus L.) during cohabitant challenge with Aeromonas salmonicida ssp. salmonicida. Aquacult Res 32:935-945

Miller VL, Mekalanos JJ (1988) A novel suicide vector and its use in construction of insertion mutations: osmoregulation of outer membrane proteins and virulence determinants in Vibrio cholerae requires toxR. J Bacteriol 170:2575-2583

> Najimi M, Lemos ML, Osorio CR (2008) Distribution of small plasmid in Aeromonas salmonicida subsp. salmonicida strains isolated from NW Spain and Portugal: evidence of clonality in strains isolated from turbot Psetta maxima (L.). J Fish Dis 31:469-472

Nougayrede P, Sochon E, Vaillaume A (1990) Isolation of Aeromonas salmonicida subspecies salmonicida in farmed turbot (Psetta maxima) in France. Bull Eur Assoc Fish Pathol 10:139-140

O'Toole R, von Hofsten J, Rosqvist R, Olsson PE, Wolf-Watz H (2004) Visualisation of zebra fish infection by GFP- 
labelled Vibrio anguillarum. Microb Pathog 37:41-46

Olivier G (1990) Virulence of Aeromonas salmonicida: lack of relationship with phenotypic characteristics. J Aquat Anim Health 2:119-127

Pedersen K, Larsen JL (1996) First report on outbreak of furunculosis in turbot Scophthalmus maximus caused by Aeromonas salmonicida subsp. salmonicida in Denmark. Bull Eur Assoc Fish Pathol 16:129-133

Pérez MJ, Fernández AIG, Rodríguez LA, Nieto TP (1996) Differential susceptibility to furunculosis of turbot and rainbow trout and release of the furunculosis agent from furunculosis-affected fish. Dis Aquat Org 26:133-137

Petersen A, Dalsgaard A (2003) Antimicrobial resistance of intestinal Aeromonas spp. and Enterococcus spp. in fish cultured in integrated broiler-fish farms in Thailand. Aquaculture 219:71-82

Reith ME, Singh RK, Curtis B, Boyd JM and others (2008) The genome of Aeromonas salmonicida subsp. salmonicida A449: insights into the evolution of a fish pathogen. BMC Genomics 9:427

Ringø E, Olsen RE, Øverli Ø, Løvik F (1997) Effect of dominance hierarchy formation on aerobic microbiota associated with epithelial mucosa of subordinate and dominant individuals of Arctic charr, Salvelinus alpinus (L.). Aquacult Res 28:901-904

Sakai DK (1985) Loss of virulence in a protease-deficient mutant of Aeromonas salmonicida. Infect Immun 48:146-152

Simon R, Priefer U, Pühler A (1983) A broad host range mobilization system for in vivo genetic engineering: transposon mutagenesis in gram negative bacteria. Nat Biotechnol 1: $784-791$

Editorial responsibility: David Bruno,

Aberdeen, UK
Svendsen YS, Dalmo RA, Bogwald J (1999) Tissue localization of Aeromonas salmonicida in Atlantic salmon, Salmo salar L., following experimental challenge. J Fish Dis 22: 125-131

Tatner MF, Johnson CM, Horne MT (1984) The tissue localization of Aeromonas salmonicida in rainbow trout, Salmo gairdneri Richardson, following three methods of administration. J Fish Biol 25:95-108

Thornton JC, Garduño RA, Newman SG, Kay WW (1991) Surface-disorganized, attenuated mutants of Aeromonas salmonicida as furunculosis live vaccines. Microb Pathog 11:85-99

Toranzo AE, Barja JL (1992) First report of furunculosis in turbot reared in floating cages in North-West of Spain. Bull Eur Assoc Fish Pathol 12:147-149

> Toranzo AE, Magariños B, Romalde JL (2005) A review of the main bacterial fish diseases in mariculture systems. Aquaculture 246:37-61

Valdivia RH, Hromockyj AE, Monack D, Ramakrishnan L, Falkow S (1996) Applications for green fluorescent protein (GFP) in the study of host-pathogen interactions. Gene 173:47-52

Ward PD, Waters CA, Sweeney KJ (1985) Autoagglutination of virulent Aeromonas salmonicida strains lacking additional surface layer. In: Ellis AE (ed) Fish and shellfish pathology. Academic Press, London, p 107-117

Welch TJ, Wiens GD (2005) Construction of a virulent, green fluorescent protein tagged Yersinia ruckeri and detection in trout tissues after intraperitoneal and immersion challenge. Dis Aquat Org 67:267-272

Submitted: September 29, 2010; Accepted: January 31, 2011 Proofs received from author(s): May 4, 2011 